\title{
Lymphatic vessel density as a prognostic indicator in Asian NSCLC patients: a meta-analysis
}

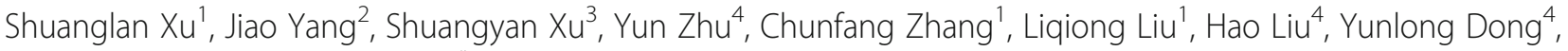 \\ Zhaowei Teng ${ }^{4}$ and Xiqian Xing ${ }^{1^{*}}$ (D)
}

\begin{abstract}
Background: To determine the association of lymphatic vessel density (LVD) with the prognosis of Asian non-small cell lung cancer (NSCLC) patients via a meta-analysis.

Methods: Eligible studies were selected by searching PubMed and EMBASE from inception to July 25, 2017. The reference lists of the retrieved articles were also consulted. The information was independently screened by two authors. When heterogeneity was significant, a random-effects model was used to determine overall pooled risk estimates.

Results: A total of 15 studies with 1075 patients were finally included in the meta-analysis. LVD was positively associated with the prognosis of NSCLC in the overall analysis (hazard ratio (HR) 1.14, 95\% confidence interval (95\% Cl): $\left.1.02-1.27, p=0.000, I^{2}=73.2 \%\right)$. Subgroup analyses were performed on 5 VEGFR-3 groups $\left(p=0.709, I^{2}=0.0 \%\right)$, 3 LYVE-1 groups $\left(p=0.01, I^{2}=86.4 \%\right), 5$ D2-40 groups $\left(p=0.019, I^{2}=66.2 \%\right)$, and 2 podoplanin groups $(p=0.094$, $\left.I^{2}=64.5 \%\right)$. Sensitivity analysis indicated robust results. There was no publication bias.
\end{abstract}

Conclusions: LVD is an indicator of poor prognosis in Asian NSCLC patients.

Keywords: NSCLC, Lymphatic vessel density, LVD, Prognostic, Meta-analysis

\section{Background}

Lung cancer is a malignant disease associated with the highest mortality rate $(18.2 \%)$ among all types of cancer worldwide [1, 2]. Non-small cell lung cancer (NSCLC) represents the majority $(\sim 85 \%)$ of all lung cancer cases, with lung adenocarcinoma (ADC) and squamous cell carcinoma (SCC) being the most frequently diagnosed histological types [3]. Approximately half of all NSCLC patients have metastasis, and this type of cancer is usually diagnosed at advanced stages. Despite great progress in treatment modalities (such as surgical resection, chemotherapy, radiotherapy, targeted therapy, biotherapy, and cellular immunotherapy), the prognosis of NSCLC remains poor, and the long-term survival of

\footnotetext{
* Correspondence: xingxiqiankm@163.com

${ }^{1}$ First Department of Respiratory Medicine, Yan'an Hospital Affiliated to Kunming Medical University, No. 245, East Renmin Road, Kunming 650051, Yunnan, China

Full list of author information is available at the end of the article
}

NSCLC patients is still dismal [4]. Thus, it is important to find novel prognostic therapeutic targets and precise prognostic markers for this type of cancer.

Cancer relapse and metastasis lead to poor prognosis. The most common mode of metastasis is lymph node metastasis. During the early stages of tumor dissemination, malignant cells spread from primary sites to regional lymph nodes. Therefore, the lymphatic system plays an important role in cancer biology [5]. The formation of new lymphatic vessels (lymphangiogenesis) occurs through several steps, including the migration, proliferation and sprouting of lymphatic endothelial cells, which are triggered by vascular endothelial growth factor receptor (VEGFR)-3, VEGF-C or VEGF-D [6]. The lymphatic vessel density (LVD) is the parameter that is most frequently used to quantify tumor lymphangiogenesis, especially for melanoma [7], oral squamous cell carcinoma [8], thyroid carcinoma [9], colorectal cancer [10], breast cancer [11], and lung cancer [12]. 
Previous studies have identified novel molecular markers of the lymphatic endothelium that have been used to study tumor-associated lymphangiogenesis via immunochemistry. These markers include VEGFR-3, Lymphatic vessel endothelial hyaluronan receptor-1 (LYVE-1), D2-40, podoplanin, Prox-1 and desmoplakin, among others [13-16]. VEGFR-3, also known as Flt4, is a member of the fms-like tyrosine kinase family, and it specifically binds VEGF-C and VEGF-D. LYVE-1 is a homolog of the vascular endothelium-specific hyaluronan receptor CD44 [17]. The antibody against D2-40 has been shown to specifically recognize the M2A antigen and podoplanin [18, 19]. Podoplanin is a glomerular podocyte membrane mucoprotein [20]. The transcription factor prox-1 is a homolog of the drosophila homeobox gene product that is involved in the regulation of early lymphatic development [21]. Desmoplakin, also known as desmosome-related transmembrane protein, is a desmosomal protein expressed at intercellular junctions. Some studies have shown that lymphatic endothelium markers can be used to predict poor prognoses in NSCLC patients [22-24], but other studies have refuted this view [25-27]. Therefore, whether LVD is a prognostic biomarker for the survival of NSCLC patients remains controversial. The aim of this meta-analysis was to examine whether LVD can predict the prognosis of Asian NSCLC patients.

\section{Methods}

\section{Search strategy}

PubMed and EMBASE were searched from inception to July 25, 2017, to find related studies. The search terms used were 1) "Non-small cell lung cancer", "Non-small cell lung carcinoma", "NSCLC", "lung adenocarcinoma", "adenocarcinoma of lung", "lung squamous cell cancer", "squamous cell cancer of the lung", "lung squamous cell carcinoma", "squamous cell carcinoma of the lung", "lung large cell cancer", "large cell cancer of the lung", "lung large cell carcinoma", and "lung large cell carcinoma"; 2) "Lymphangiogenesis", "Lymphangiogeneses", "Lymphatic microvessel density", "Lymphatic vessel density", "Lymphatic microvessel", and "Lymphatic vessel"; and 3) "prognostic", "prognosis", and "survival".

\section{Study selection}

The inclusion criteria were as follows: 1) a cohort study; 2) an Asian study population; 3) diagnosis of NSCLC based on lung histology, with the most important histological types being ADC, SCC and large cell cancer (LCC); 4) evaluation of the association between LVD and the prognosis of NSCLC patients; 5) analysis of lymph microvessel markers by immunohistochemistry; and 6) the presence of sufficient data to calculate the adjusted hazard ratio (HR) or risk ratio (RR) and the corresponding 95\% confidence intervals (CIs). Studies were excluded if they had non-human study subjects. If the data were duplicated or the same population was used in more than one study, we chose the most recent or complete study.

\section{Data extraction}

The eligible studies selected for our meta-analysis were independently evaluated by two reviewers (XXQ and XSL) based on the aforementioned selection criteria. The following information was extracted from the eligible studies: the name of the first author, publication year, study period, country, sample number, sex of patients, median follow-up period, mean age or age range of patients, histology, histological type, TNM stage, and lymphatic endothelium markers (in Table 1). In addition, $\mathrm{HR}$ and 95\% CIs were evaluated. Two authors (TZW and XSY) summarized the extracted data. Any disagreements were resolved by discussion.

\section{Statistical analyses}

To compute a pooled HR with a $95 \% \mathrm{CI}$, the Q-test and the $\mathrm{I}^{2}$ test were used to assess heterogeneity among the studies [28]. We also calculated $P$ values for the Q-test, which represented heterogeneity; heterogeneity was present if the $\mathrm{P}$ value was less than 0.10 . The random-effects model was applied when $\mathrm{I}^{2}>50 \%$ [29]; otherwise, the fixed-effects model was applied [30]. Subgroup analyses based on lymphatic endothelium markers were performed to further explore the source of heterogeneity. Additionally, Begg's rank correlation test and Egger's linear regression test were conducted to assess the extent of potential publication bias [31]. Finally, a sensitivity analysis was performed by sequentially omitting one study per cycle to evaluate the stability of the results [32]. The data analyses were conducted using the STATA statistical software version 12.0 (STATA Corp. LLC, College Station, TX, USA).

\section{Results}

Literature search and study characteristics

Using the predefined search strategy and inclusion criteria, 15 studies [22-27, 33-41] involving 1075 participants were ultimately included in this meta-analysis. The detailed study selection process is presented in Fig. 1. In total, 251 articles (108 from PubMed and 143 from EMBASE) were retrieved. Among these articles, 236 articles were excluded after eliminating duplicates, screening the titles and abstracts, and reviewing the full text. Finally, 15 articles were included in our analysis.

The characteristics of the 15 eligible studies are shown in Table 1. These studies included 1075 participants from Asia, including Japan and China;a total of 11 studies investigated NSCLC, 3 studies investigated ADC, and 1 study investigated lung cancer. All studies used immunohistochemistry 
Table 1 Characteristics of the 15 studies

\begin{tabular}{|c|c|c|c|c|c|c|c|c|c|c|c|c|}
\hline \multirow{2}{*}{$\begin{array}{l}\text { Author-year } \\
\text { (study period) Country }\end{array}$} & \multirow{2}{*}{$\begin{array}{l}\text { Sample } \\
\text { number }\end{array}$} & \multicolumn{2}{|l|}{ Sex } & \multirow{2}{*}{$\begin{array}{l}\text { Median follow-up } \\
\text { period (months) }\end{array}$} & \multirow{2}{*}{$\begin{array}{l}\text { Age: mean } \\
\text { age or range }\end{array}$} & \multirow[t]{2}{*}{ Histology } & \multicolumn{4}{|c|}{ Histological type } & \multirow{2}{*}{$\begin{array}{l}\text { TNM } \\
\text { stage }\end{array}$} & \multirow{2}{*}{$\begin{array}{l}\text { Lymphatic } \\
\text { endothelium } \\
\text { markers }\end{array}$} \\
\hline & & Males & Females & & & & $\overline{A D C}$ & SCC & LCC & Others & & \\
\hline $\begin{array}{l}\text { Kitano-2017 } \\
\text { (1988-2010) Japan [33] }\end{array}$ & 89 & 64 & 25 & range $10-153$ & $\begin{array}{l}<60 \text { y } 25 \\
\geq 60 \text { y } 64\end{array}$ & NSCLC & 53 & 36 & 0 & 0 & $\begin{array}{l}\| 40 \text { III } \\
+ \text { IV } 49\end{array}$ & VEGFR-3 \\
\hline $\begin{array}{l}\text { Nunomiya-2014 } \\
\text { (2008-2011) Japan [25] }\end{array}$ & 58 & 50 & 8 & ND & 71.3 y & $\begin{array}{l}\text { NSCLC } 40 \\
\text { SCLC } 14 \\
\text { Others } 4\end{array}$ & ND & ND & ND & ND & $\begin{array}{l}\text { I + II } 20 \text { III } \\
+ \text { IV } 37\end{array}$ & LYVE-1 \\
\hline $\begin{array}{l}\text { Hao-2014 } \\
\text { (2004-2012) China [34] }\end{array}$ & 140 & 72 & 68 & ND & $\begin{array}{l}\leq 65 \text { y } 56 \\
>65 \text { y } 84\end{array}$ & NSCLC & 36 & 39 & 28 & 4 & $|-||| A$ & LYVE-1 \\
\hline $\begin{array}{l}\text { Zhang-2012 } \\
\text { (2003-2006) China [22] }\end{array}$ & 65 & 38 & 27 & ND & $\begin{array}{l}51.5 \text { y } \\
\text { (range } 32-76 \text { y) } \\
<55 \text { y } 26 \\
\geq 55 \text { y } 39\end{array}$ & ADC & 65 & 0 & 0 & 0 & $\begin{array}{l}\text { I+ II } 38 \text { III } \\
+ \text { IV } 27\end{array}$ & D2-40 \\
\hline $\begin{array}{l}\text { Dai-2011 } \\
\text { (1999-2003) China [35] }\end{array}$ & 98 & ND & ND & $37.53 \pm 4.05$ & ND & NSCLC & 59 & 39 & 0 & 0 & ND & Podoplanin \\
\hline $\begin{array}{l}\text { Yamashita-2010 } \\
\text { (1993-2000) Japan [36] }\end{array}$ & 117 & 77 & 40 & 68.7 & $\begin{array}{l}67.8 \text { y (range } \\
47-85 \text { y) } \\
<68 \text { y } 67 \\
\geq 68 \text { y } 50\end{array}$ & $\begin{array}{l}\text { Stage I } \\
\text { NSCLC }\end{array}$ & 78 & 31 & 6 & 2 & $\begin{array}{l}\text { IA } 58 \\
\text { IB } 59\end{array}$ & VEGFR-3 \\
\hline $\begin{array}{l}\text { Chen-2010 } \\
\text { (1999-2001) China [37] }\end{array}$ & 52 & 41 & 11 & ND & $\begin{array}{l}51.9 \text { y } \\
\text { (range } 29-77 \text { y) } \\
<60 \text { y } 31 \\
\geq 60 \text { y } 21\end{array}$ & NSCLC & 16 & 23 & 0 & 13 & $\begin{array}{l}1+1 \mid 33 \\
\text { III } 19\end{array}$ & LYVE-1 \\
\hline $\begin{array}{l}\text { Sun-2009 } \\
(1995-2004) \text { China [38] }\end{array}$ & 82 & 63 & 19 & ND & $\begin{array}{l}<55 \text { y } 40 \\
\geq 55 \text { y } 42\end{array}$ & NSCLC & 41 & 31 & 10 & 0 & $\begin{array}{l}\text { I+ II } 48 \\
\text { III + IV } 34\end{array}$ & D2-40 \\
\hline $\begin{array}{l}\text { Iwakiri-2009 } \\
\text { (1998-1990) Japan [39] }\end{array}$ & 215 & 159 & 56 & ND & $\begin{array}{l}63.0 \text { y } \\
\text { (range } 53-71.8 \\
\text { y) } \\
<63 \text { y } 109 \\
\geq 63 \text { y } 106\end{array}$ & $\mathrm{NSCLC}$ & 116 & 82 & 10 & 7 & $\begin{array}{l}\text { I+ II } 147 \\
\text { IIIA } 68\end{array}$ & D2-40 \\
\hline $\begin{array}{l}\text { Kitano-2009 (ND) } \\
\text { Japan [23] }\end{array}$ & 82 & 45 & 37 & ND & $65 y$ & $A D C$ & 82 & 0 & 0 & 0 & $\begin{array}{l}\text { I+ II } 65 \\
\text { III + IV } 17\end{array}$ & Podoplanin \\
\hline $\begin{array}{l}\text { Kadota-2008 } \\
\text { (1998-2002) Japan [24] }\end{array}$ & 147 & 100 & 47 & ND & $\begin{array}{l}67 \text { y } \\
\text { (range 35-82 y) }\end{array}$ & NSCLC & 93 & 49 & 5 & 0 & $\begin{array}{l}\text { I+ II } 108 \\
\text { III } 39\end{array}$ & D2-40 \\
\hline $\begin{array}{l}\text { Ohta-2006 } \\
\text { (1981-2004) Japan [40] }\end{array}$ & 44 & 23 & 21 & 20 & 64.4 y & NSCLC & 25 & 17 & 0 & 2 & $\begin{array}{l}\text { IIIA } 35 \\
\text { IIIB } 9\end{array}$ & D2-40 \\
\hline $\begin{array}{l}\text { Kojima-2005 } \\
\text { (1981-1998) Japan [26] }\end{array}$ & 129 & 62 & 67 & 69.9 & $\begin{array}{l}61 \text { y } \\
\text { (range 38-78 y) }\end{array}$ & ADC & 129 & 0 & 0 & 0 & ND & VEGFR-3 \\
\hline $\begin{array}{l}\text { Chen-2004 } \\
\text { (1985-1990) Japan [41] }\end{array}$ & 206 & 148 & 58 & ND & $\begin{array}{l}<64 \text { y } 101 \\
\geq 64 \text { y } 105\end{array}$ & NSCLC & 116 & 75 & 10 & 5 & $\begin{array}{l}\text { I+ II } 144 \\
\text { IIIA } 62\end{array}$ & VEGFR-3 \\
\hline $\begin{array}{l}\text { Arinaga-2003 } \\
\text { (1990-1996) Japan [27] }\end{array}$ & 180 & 133 & 47 & 54.6 & $\begin{array}{l}65 y \\
\text { (range 35-84 y) }\end{array}$ & NSCLC & 65 & 101 & 0 & 14 & $\begin{array}{l}\text { I+ || } 130 \\
\text { I|| } 41\end{array}$ & VEGFR-3 \\
\hline
\end{tabular}

NSCLC non-small cell lung carcinoma, SCLC small cell lung carcinoma, $A D C$ adenocarcinoma, SCC squamous cell cancer, $L C C$ large cell cancer, VEGFR-3 vascular endothelial growth factor receptor-3, LYVE-1 lymphatic vessel endothelial receptor 1, y year, ND no data

to assess LVD using different lymphatic endothelium markers, including VEGFR-3 in 5 studies, LYVE-1 in 3 studies, D2-40 in 5 studies, podoplanin in 2 studies.

\section{Main analysis}

LVD was positively associated with the prognosis of NSCLC in the overall analysis (HR 1.14, 95\% CI: 1.02-1.27) (Fig. 2). However, significant heterogeneity was detected across studies $\left(\mathrm{I}^{2}=73.2 \% ; P=0.000\right)$.

\section{Subgroup meta-analysis}

The results of subgroup analyses using the lymphatic endothelium markers that were selected to evaluate LVD via immunohistochemistry support our findings. A positive relationship was observed between the expression of lymphatic endothelium markers and the prognoses of NSCLC patients $\left(p=0.000, \mathrm{I}^{2}=73.2 \%\right)$. No statistically significant heterogeneity was observed in the 5 VEGFR-3 group ( $\left.p=0.709, \mathrm{I}^{2}=0.0 \%\right)$; however, there was considerable heterogeneity in the 3 LYVE-1 groups ( $\left.p=0.01, \mathrm{I}^{2}=86.4 \%\right)$, 


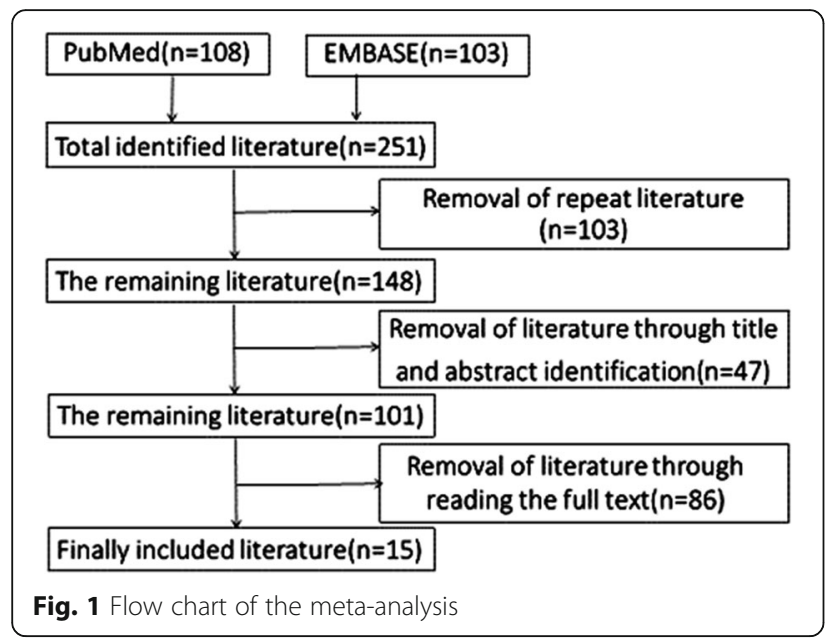

the $5 \mathrm{D} 2-40$ groups $\left(p=0.019, \mathrm{I}^{2}=66.2 \%\right)$ and the 2 podoplanin groups $\left(p=0.094, \mathrm{I}^{2}=64.5 \%\right)$ (Fig. 3). Nevertheless, the data were not sufficient to determine the prognostic value of LVD among Asian populations based on sex, median follow-up period, mean age or age range, histological type, or TNM stage.

\section{Sensitivity analysis}

To evaluate the robustness of our analysis, we conducted a sensitivity analysis by recalculating the pooled results from the primary analyses after excluding one study per iteration. None of the studies when excluded altered the overall combined results (Fig. 4).

\section{Publication bias}

No evidence of publication bias was found based on the Begg's rank correlation test $(p>|z|=0.488)$ or Egger's linear regression test $(p>|z|=0.133)$ (Figs. 5 and 6).

\section{Discussion}

NSCLC is the most common subtype of lung cancer, with a high incidence, high mortality, low survival rate, low diagnosis rate and treatment rate. It has been challenging to improve survival rates due to the lack of precise prognostic markers. To overcome this problem, a comprehensive understanding of lymphatic endothelium markers is needed. It is important to examine whether LVD can be an indicator of the prognosis in Asian NSCLC patients.

In our present meta-analysis, LVD was positively associated with the prognosis of NSCLC (HR: 1.14, 95\% CI: 1.02-1.27), indicating that high LVD indeed predicts poor survival in Asian NSCLC populations. To date, only Wang and colleagues [42] have described the relationship between LVD and the prognoses of NSCLC patients worldwide. Nevertheless, there was considerable heterogeneity among the included studies, which may make the results unreliable. However, sensitivity analysis did not reveal the source of heterogeneity. Furthermore, subgroup analyses were conducted using lymphatic endothelium markers. Additionally, publication bias was detected. Our study only focused on Asian patients, and thus our results are applicable for Asian populations. Although heterogeneity was also observed, the findings

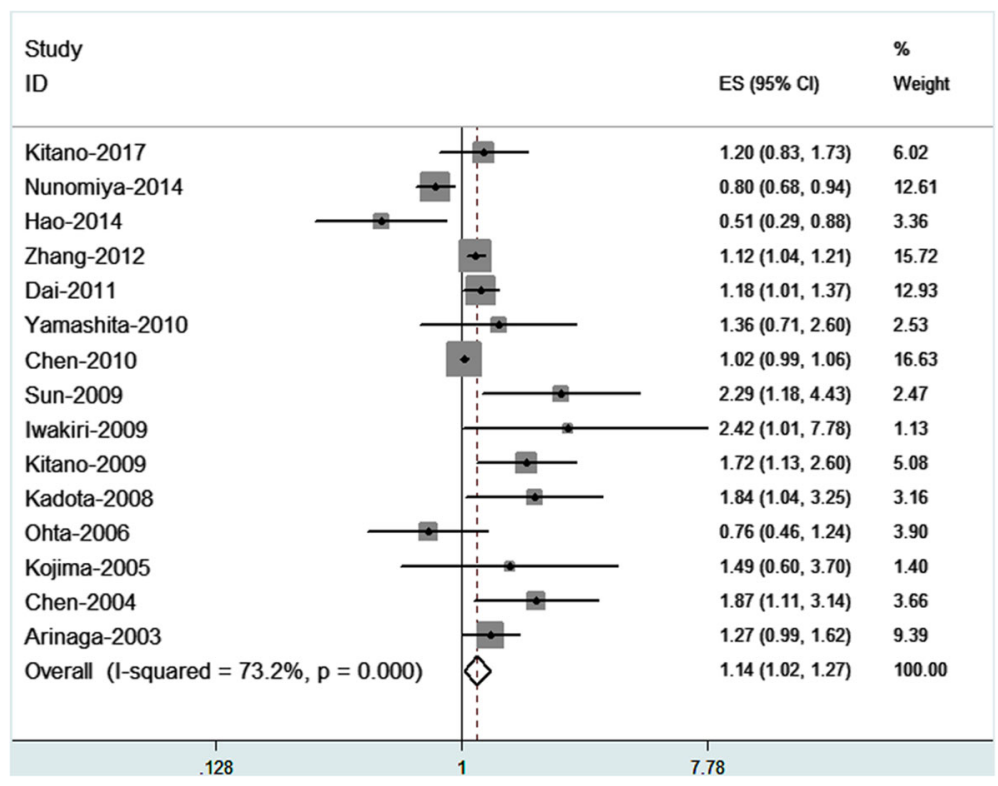

Fig. 2 Forest plot of LVD associated with NSCLC prognosis 


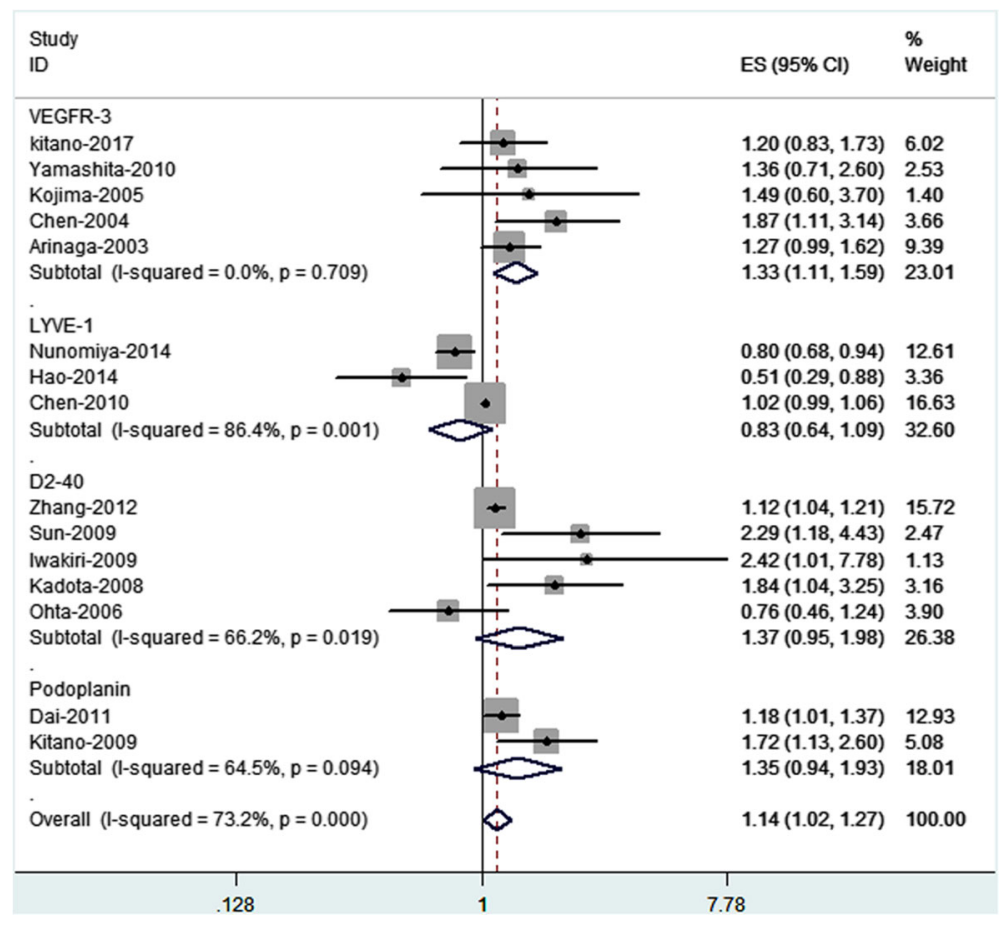

Fig.3 Subgroup analysis of LVD associated with NSCLC prognosis

were stable and robust based on our sensitivity analysis. In addition, subgroup analyses were performed based on the four lymphatic endothelium markers to further explore the origin of heterogeneity. Except VEGFR-3, the other three markers gave rise to considerable heterogeneity. Our meta-analysis included five additional studies that were more recent than those included in the study by Wang and colleagues. Moreover, no publication bias was observed in our study. The study by Zheng and colleagues [43] showed that the VEGF family is important for tumorigenesis and metastasis and that high VEGF and/or VEGFR expression, especially VEGF-C/VEGFR-3 co-expression, is indicative of poor survival in patients with NSCLC. However, that study did not evaluate other lymphatic endothelium markers, which were included in subgroup analyses in our study.

The role of LVD as a prognostic predictor in NSCLC remains controversial. Kajita and colleagues were the first to report VEGFR-3 expression in lung cancer cells, but they did not evaluate its impact on the prognosis or

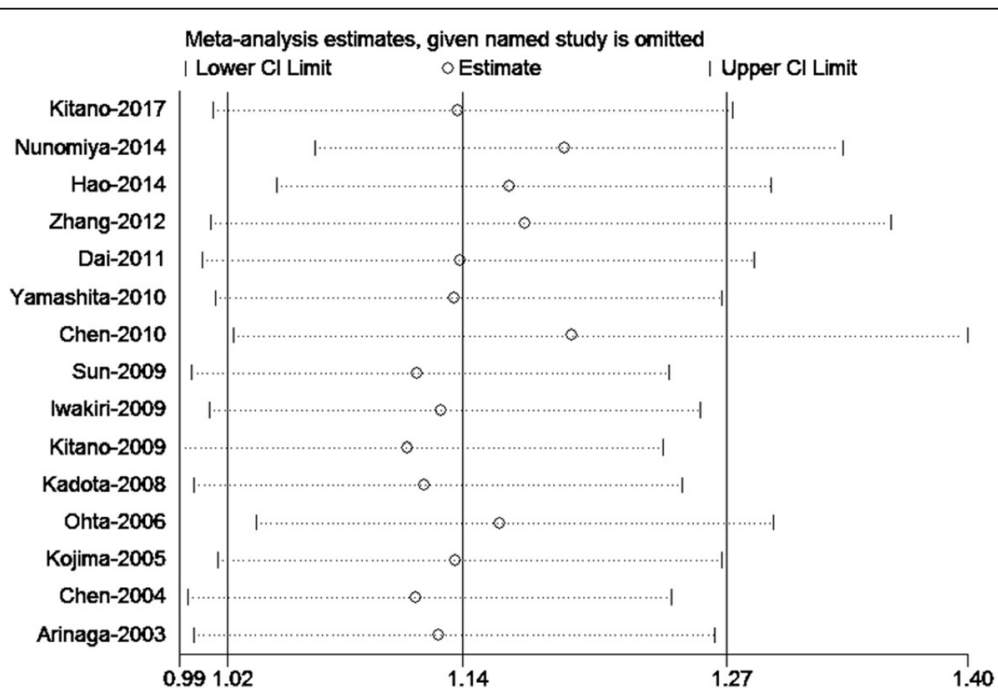

Fig. 4 Sensitivity analysis of LVD associated with NSCLC prognosis 


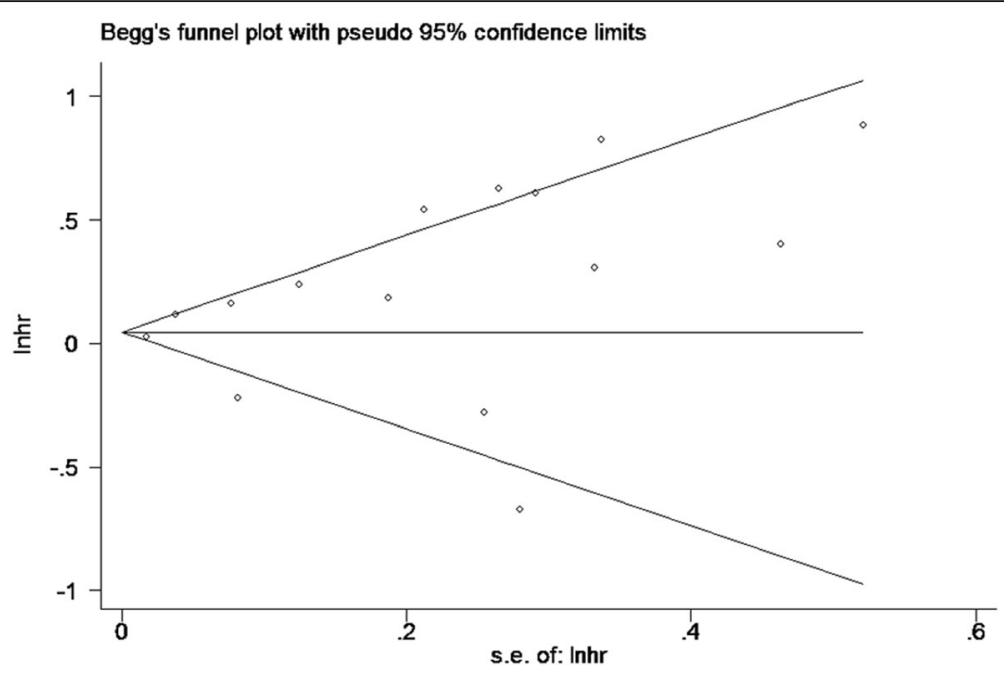

Fig. 5 Begg's funnel plot

the correlation of VEGFR-3 expression with clinicopathologic features in patients with NSCLC [44]. Later, many studies demonstrated that VEGF-C, VEGF-D, VEGFR-3 and other markers are independent markers of poor prognostic in patients with NSCLC. Thus, these markers may be ideal targets for diagnosis or therapy to improve the prognosis of NSCLC patients [34]. The study by Arinaga demonstrated that the combined expression of VEGF-C and VEGFR-3 has a negative impact on the prognosis of patients with NSCLC [27]. In addition, the study by Zhang and colleagues revealed that D240-positive peritumoral LVD may be an independent prognostic factor for lung adenocarcinoma. Thus, D240-positivity may be used to predict patient prognosis in lung adenocarcinoma. Moreover, the reduction of peritumoral lymphangiogenesis has been suggested to inhibit the metastasis of lung adenocarcinoma [22]. However, some studies have claimed that high LVD may be a marker for good prognosis. The study by Nunomiya and colleagues showed that lung cancer patients with lower LYVE-1 levels have poorer prognoses than patients with higher LYVE-1 levels [25]. Yang and his team demonstrated the role of the epigenetic regulation of desmoplakin in increasing the sensitivity of cancer cells to anticancer drug-induced apoptosis, implying the clinical value of desmoplakin for the treatment of patients with lung cancer [45]. Nevertheless, more studies are needed in the near future to verify whether LVD is indicative of good or bad prognosis in NSCLC patients.

VEGFR-3, D2-40, LYVE-1 and podoplanin are widely used and extremely valuable markers of lymphatic vessels. However, one study has reported that lymphatic

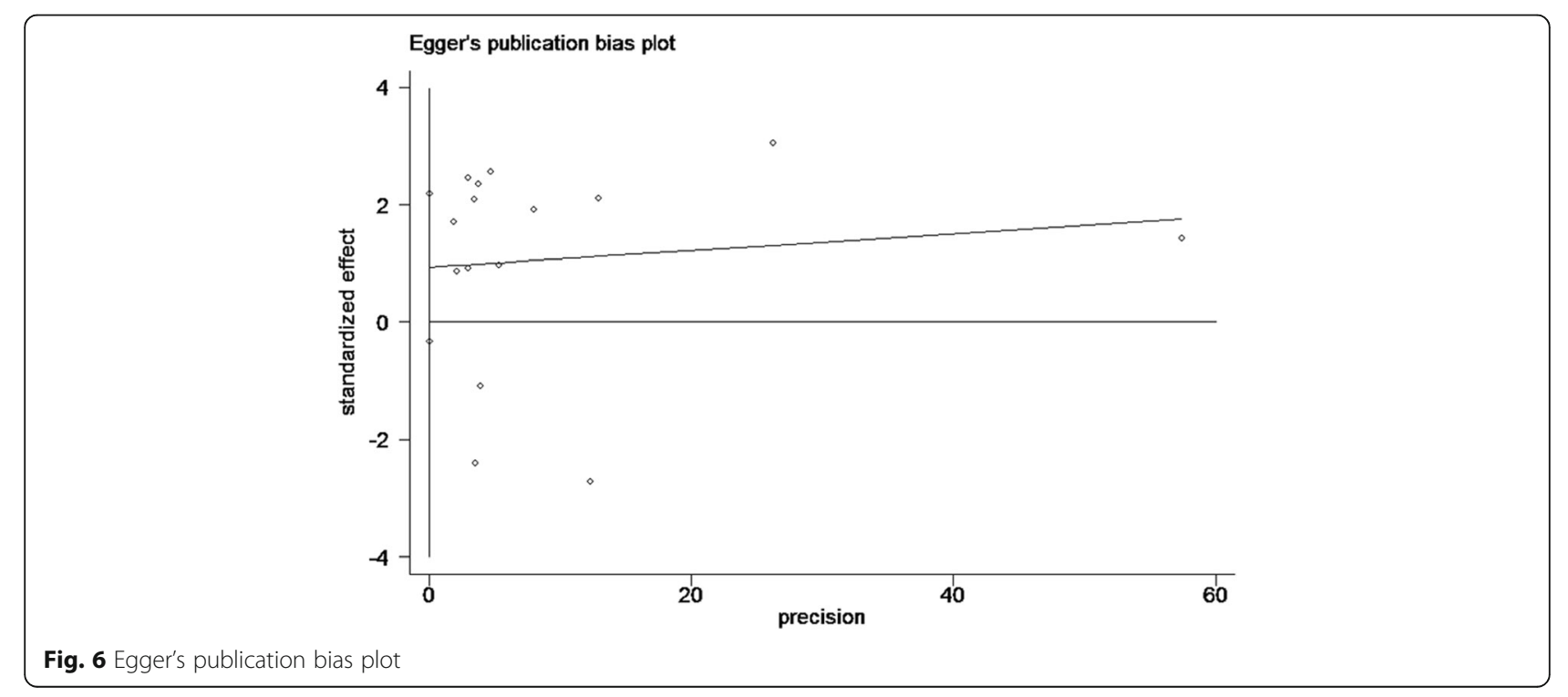


endothelium markers are not only expressed on lymphatic vessels but also expressed on blood vessels, tumor cells or in normal tissues [13]. One of the major drawbacks is the lack of specific markers for the lymphatic endothelium. One study [46] indicated that LYVE-1 and Prox-1 are molecular markers of lymphangiogenesis in NSCLC and that they can be used as important markers for the evaluation of lymphatic metastasis and prognoses in patients with NSCLC. Another study [43] showed that high VEGF and/or VEGFR expression is indicative of poor survival in patients with NSCLC and that VEGF-C/ VEGFR-3 co-expression is a better prognostic indicator than other markers. Therefore, the evaluation of co-expressed markers may be useful to determine LVD.

Irrespective of its strengths, the meta-analysis also has certain limitations. First, although we searched all retrospective studies for the association between LVD and the prognosis of NSCLC, the eligible studies were restricted to those published in English or Chinese. Because of linguistic barrier, some non-English or non-Chinese studies were excluded. In addition, we also missed some studies that may have been published in books or journals that were not available in the online databases. Additionally, studies with negative data may not have been submitted by investigators, or studies with nonsignificant results may have been rejected by journals. Nevertheless, there was no significant publication bias in our study, although we could not completely rule out publication bias. Second, few studies did not present clear or complete data, making data analysis difficult. When we could not obtain original data from the authors via email or other means, we had to exclude those studies. Third, because of the small number of eligible articles, our study was not the most comprehensive. Fourth, our results cannot be generalized to populations worldwide, especially non-Asian populations. Thus, more comprehensive and higher quality analyses are still required in the future.

\section{Conclusions}

In summary, this meta-analysis indicated that LVD is an indicator of the prognosis of Asian NSCLC patients. However, higher quality and more comprehensive analyses are still needed as more data are published in the future.

\footnotetext{
Abbreviations

95\% Cl: 95\% confidence interval; ADC: Adenocarcinoma; HR: Hazard ratio; LCC: Large cell cancer; LVD: Lymphatic vessel density; LYVE-1: Lymphatic vessel endothelial hyaluronan receptor-1; NSCLC: Non-small cell lung cancer; SCC: Squamous cell carcinoma; VEGFR: Vascular endothelial growth factor receptor
}

\section{Acknowledgments}

We appreciate the contribution of all patients, their families, the investigators and the medical staff. We are grateful to all authors.

\section{Funding}

This study was supported by grants from the National Natural Science Foundation of China (No. 81560694 and 81760015), the Young Academic and Technical Leaders of Yunnan Province (No. 2017HB053), and the Medical Science Leaders of Yunnan Province (No. 201627).

\section{Availability of data and materials}

All data analyzed during this study are included in this published article.

\section{Authors' contributions}

XSL and XXQ were responsible for the initial plan, study design, data collection, data extraction, data interpretation, manuscript drafting, statistical analysis, and performance of the study. TZW and XSY were responsible for critical revision of the manuscript. YJ, ZY, ZCF, LLQ, LH and DYL were responsible for data interpretation, manuscript drafting, supervision, and critical revision of the manuscript. XSL and TZW act as the guarantors for this article and take full responsibility for this study. All authors have read and approved the final manuscript.

\section{Ethics approval and consent to participate}

Not applicable.

Consent for publication

Not applicable.

Competing interests

The authors declare that they have no competing interests.

\section{Publisher's Note}

Springer Nature remains neutral with regard to jurisdictional claims in published maps and institutional affiliations.

\section{Author details}

1First Department of Respiratory Medicine, Yan'an Hospital Affiliated to Kunming Medical University, No. 245, East Renmin Road, Kunming 650051, Yunnan, China. ${ }^{2}$ First Department of Respiratory Medicine, The First Affiliated Hospital of Kunming Medical University, Kunming 650032, Yunnan, China. ${ }^{3}$ Department of Dermatology, The Second Affiliated Hospital of Kunming Medical University, Kunming 650032, Yunnan, China. ${ }^{4}$ The People's Hospital of Yuxi City, The 6th Affiliated Hospital of Kunming Medical University, Yuxi 653100, Yunnan, China.

Received: 15 May 2018 Accepted: 31 July 2018

Published online: 06 August 2018

\section{References}

1. Siegel RL, Miller KD, Jemal A. Cancer statistics, 2017. CA Cancer J Clin. 2017; 67:7-30.

2. Torre LA, Bray F, Siegel RL, Ferlay J, Lortet-Tieulent J, Jemal A. Global cancer statistics, 2012. CA Cancer J Clin. 2015;65:87-108. https://doi.org/10.3322/ caac.21262. (Epub 2015 Feb 4)

3. Li J, Li D, Wei X, Su Y. In silico comparative genomic analysis of two nonsmall cell lung cancer subtypes and their potentials for cancer classification. Cancer Genomics Proteom. 2014;11:303-10.

4. Tang Z, Li J, Shen Q, Feng J, Liu H, Wang W, et al. Contribution of upregulated dipeptidyl peptidase 9 (DPP9) in promoting tumoregenicity, metastasis and the prediction of poor prognosis in non-small cell lung cancer (NSCLC). Int J Cancer. 2017;140:1620-32. https://doi.org/10.1002/ijc. 30571. (Epub 2017 Feb 2)

5. Dai C, Ren Y, Xie D, Zheng H, She Y, Fei K, et al. Does lymph node metastasis have a negative prognostic impact in patients with NSCLC and M1a disease? J Thorac Oncol Off Publ Int Assoc Study Lung Cancer. 2016;11: 1745-54. https://doi.org/10.1016/j.jtho.2016.06.030. (Epub 2016 Aug 24)

6. Pérez-Guijarro E, Merlino G. Lymphangiogenesis: from passive disseminator to dynamic metastatic enabler. Pigment Cell Melanoma Res. 2017;30:50910. https://doi.org/10.1111/pcmr.12621. (Epub 2017 Oct 16)

7. Špirić Z, Eri Ž, Erić M. Lymphatic vessel density and VEGF-C expression as independent predictors of melanoma metastases. J Plast Reconstr Aesthet Surg JPRAS. 2017;70:1653-9. https://doi.org/10.1016/j.bjps.2017.06.040. (Epub 2017 Sep 13) 
8. Abdul-Aziz MA, Amin AK, El-Rouby DH, Shaker OG. Lymphangiogenesis in oral squamous cell carcinoma: correlation with VEGF-C expression and lymph node metastasis. Int J Dent. 2017;2017:7285656. https://doi.org/10. 1155/2017/7285656. (Epub 2017 Jun 7)

9. Pereira F, Pereira SS, Mesquita M, Morais T, Costa MM, Quelhas P, et al. Lymph node metastases in papillary and medullary thyroid carcinoma are independent of intratumoral lymphatic vessel density. Eur Thyroid J. 2017;6: 57-64. https://doi.org/10.1159/000457794. (Epub 2017 Mar 17)

10. Pappas A, Lagoudianakis E, Seretis C, Koronakis N, Keramidaris D, Grapatsas $K$, et al. Role of lymphatic vessel density in colorectal cancer: prognostic significance and clinicopathologic correlations. Acta Gastroenterol Belg. 2015;78:223-7

11. Niemiec JA, Adamczyk A, Ambicka A, Mucha-Małecka A, Wysocki WM, Biesaga B, et al. Prognostic role of lymphatic vessel density and lymphovascular invasion in chemotherapy-naive and chemotherapy-treated patients with invasive breast cancer. Am J Transl Res. 2017;9:1435-47.

12. Wang G, Wang Z, Li C, Wang P, Chai D, Cheng Z. Relationship among the expression of lymphatic vessel density, microvessel density, carcinoembryonic antigenic mRNA, KAl1, and Kiss-1, and prognosis in patients with non-small cell lung cancer. Zhongguo Fei Ai Za Zhi. 2012;15: 348-54. https://doi.org/10.3779/j.issn.1009-3419.2012.06.05.

13. Cueni LN, Detmar M. New insights into the molecular control of the lymphatic vascular system and its role in disease. J Invest Dermatol. 2006; 126:2167-77.

14. Waś $\mathrm{H}$. Characterization of markers and growth factors for lymphatic endothelium. Postepy Biochem. 2005;51:209-14.

15. Lingtong W, Qiangxiu W. Lymphatic endothelium-specific markers: A Systematic Review. Shandong Med. 2008;48:114-5.

16. YU S, Binquan W. Lymphatic endothelium-specific markers. A Systematic Review. J Shanxi Med Univ 2007;03:274-77.

17. Banerji S, Ni J, Wang SX, Clasper S, Su J, Tammi R, et al. LYVE-1, a new homologue of the CD44 glycoprotein, is a lymph-specific receptor for hyaluronan. J Cell Biol. 1999;144:789-801.

18. Kahn HJ, Bailey D, Marks A. Monoclonal antibody D2-40, a new marker of lymphatic endothelium, reacts with Kaposi's sarcoma and a subset of angiosarcomas. Mod Pathol. 2002;15:434-40.

19. Van den Eynden GG, Van der Auwera I, Van Laere SJ, Huygelen V, Colpaert CG, van Dam P, et al. Induction of lymphangiogenesis in and around axillary lymph node metastases of patients with breast cancer. Br J Cancer. 2006;95: 1362-6.

20. Breiteneder-Geleff S, Soleiman A, Kowalski H, Horvat R, Amann G, Kriehuber $E$, et al. Angiosarcomas express mixed endothelial phenotypes of blood and lymphatic capillaries: podoplanin as a specific marker for lymphatic endothelium. Am J Pathol. 1999;154:385-94.

21. Wigle JT, Oliver G. Prox1 function is required for the development of the murine lymphatic system. Cell. 1999;98:769-78.

22. Zhang BC, Guan S, Zhang YF, Yao GQ, Yang B, Zhao Y, et al. Peritumoral lymphatic microvessel density is related to poor prognosis in lung adenocarcinoma: a retrospective study of 65 cases. Exp Ther Med. 2012;3: 636-40.

23. Kitano H, Kageyama S, Hewitt SM, Hayashi R, Doki Y, Ozaki Y, et al. Podoplanin expression in cancerous stroma induces lymphangiogenesis and predicts lymphatic spread and patient survival. Arch Pathol Lab Med. 2010;134:1520-7. https://doi.org/10.1043/2009-0114-OA.1.

24. Kadota K, Huang CL, Liu D, Ueno M, Kushida Y, Haba R, et al. The clinical significance of lymphangiogenesis and angiogenesis in non-small cell lung cancer patients. Eur J Cancer. 2008;44:1057-67. https://doi.org/10.1016/j.ejca. 2008.03.012. (Epub 2008 Apr 8)

25. Nunomiya K, Shibata Y, Abe S, Inoue S, Igarashi A, Yamauchi K, et al. Relationship between serum level of lymphatic vessel endothelial hyaluronan Receptor-1 and prognosis in patients with lung cancer. J Cancer. eCollection. 2014;2014(5):242-7. https://doi.org/10.7150/jca.8486.

26. Kojima H, Shijubo N, Yamada G, Ichimiya S, Abe S, Satoh M, et al. Clinical significance of vascular endothelial growth factor- $\mathrm{C}$ and vascular endothelial growth factor receptor 3 in patients with T1 lung adenocarcinoma. Cancer. 2005;104:1668-77.

27. Arinaga M, Noguchi T, Takeno S, Chujo M, Miura T, Uchida Y. Clinical significance of vascular endothelial growth factor $C$ and vascular endothelial growth factor receptor 3 in patients with nonsmall cell lung carcinoma. Cancer. 2003;97:457-64.
28. Higgins JP, Thompson SG, Deeks JJ, Altman DG. Measuring inconsistency in meta-analyses. BMJ. 2003;327:557-60.

29. Higgins JP, Thompson SG. Quantifying heterogeneity in a meta-analysis. Stat Med. 2002;21:1539-58.

30. Leonard T, Duffy JC. A Bayesian fixed effects analysis of the mantel-Haenszel model applied to meta-analysis. Stat Med. 2002;21:2295-312.

31. Harbord RM, Egger M, Sterne JA. A modified test for small-study effects in meta-analyses of controlled trials with binary endpoints. Stat Med. 2006;25: 3443-57.

32. Chootrakool H, Shi JQ, Yue R. Meta-analysis and sensitivity analysis for multiarm trials with selection bias. Stat Med. 2011;30:1183-98. https://doi.org/10. 1002/sim.4143. (Epub 2011 Jan 16)

33. Kitano H, Chung JY, Noh KH, Lee YH, Kim TW, Lee SH, et al. Synaptonemal complex protein 3 is associated with lymphangiogenesis in non-small cell lung cancer patients with lymph node metastasis. J Transl Med. 2017;15:138. https://doi.org/10.1186/s12967-017-1241-5.

34. Hao S, Yang Y, Liu Y, Yang S, Wang G, Xiao J, et al. JAM-C promotes lymphangiogenesis and nodal metastasis in non-small cell lung cancer. Tumour Biol. 2014;35:5675-87. https://doi.org/10.1007/s13277-014-1751-1. (Epub 2014 Mar 2)

35. Dai $X$, Wang W, Shen-Tu Y, Zhang J. Expression and prognostic value of VEGF-C and lymphangeogenesis in lung adenocarcinoma and squamous cell carcinoma. Zhongguo Fei Ai Za Zhi. 2011;14:774-9. https://doi.org/10. 3779/j.issn.1009-3419.2011.10.02.

36. Yamashita T, Uramoto H, Onitsuka T, Ono K, Baba T, So T, et al. Association between lymphangiogenesis-/micrometastasis- and adhesion-related molecules in resected stage I NSCLC. Lung Cancer. 2010;70:320-8. https:// doi.org/10.1016/j.lungcan.2010.02.013. (Epub 2010 Apr 2)

37. Chen X, Wan J, Liu J, Xie W, Diao X, Xu J, et al. Increased IL-17-producing cells correlate with poor survival and lymphangiogenesis in NSCLC patients. Lung Cancer. 2010;69:348-54. https://doi.org/10.1016/j.lungcan.2009.11.013.

38. Sun JG, Wang Y, Chen ZT, Zhuo WL, Zhu B, Liao RX, et al. Detection of lymphangiogenesis in non-small cell lung cancer and its prognostic value. J Exp Clin Cancer Res. 2009;28:21. https://doi.org/10.1186/1756-9966-28-21.

39. Iwakiri S, Nagai S, Katakura H, Takenaka K, Date H, Wada H, et al. D2-40positive lymphatic vessel density is a poor prognostic factor in squamous cell carcinoma of the lung. Ann Surg Oncol. 2009;16:1678-85. https://doi. org/10.1245/s10434-009-0432-6. (Epub 2009 Mar 28)

40. Ohta Y, Shimizu Y, Minato H, Matsumoto I, Oda M, Watanabe G. Results of initial operations in non-small cell lung cancer patients with single-level N2 disease. Ann Thorac Surg. 2006;81:427-33.

41. Chen F, Takenaka K, Ogawa E, Yanagihara K, Otake Y, Wada H, et al. Flt-4positive endothelial cell density and its clinical significance in non-small cell lung cancer. Clin Cancer Res. 2004;10:8548-53.

42. Wang J, Li K, Wang B, Bi J. Lymphatic microvessel density as a prognostic factor in non-small cell lung carcinoma: a meta-analysis of the literature. Mol Biol Rep. 2012;39:5331-8. https://doi.org/10.1007/s11033-011-1332-y. (Epub 2011 Dec 14)

43. Zheng CL, Qiu C, Shen MX, Qu X, Zhang TH, Zhang JH, et al. Prognostic impact of elevation of vascular endothelial growth factor family expression in patients with non-small cell lung cancer: an updated meta-analysis. Asian Pac J Cancer Prev. 2015;16:1881-95.

44. Kajita T, Ohta Y, Kimura K, Tamura M, Tanaka Y, Tsunezuka Y, et al. The expression of vascular endothelial growth factor $C$ and its receptors in nonsmall cell lung cancer. Br J Cancer. 2001;85:255-60.

45. Yang L, Chen Y, Cui T, Knösel T, Zhang Q, Albring KF, et al. Desmoplakin acts as a tumor suppressor by inhibition of the Wnt/beta-catenin signaling pathway in human lung cancer. Carcinogenesis. 2012;33:1863-70. https:// doi.org/10.1093/carcin/bgs226. (Epub 2012 Jul 12)

46. Chang C, Wang P, Yang H, Li L, Zhang LB. Expression of LYVE-1 and Prox-1 in non-small cell lung cancer and the relationship with lymph node metastasis. Sichuan Da Xue Xue Bao Yi Xue Ban. 2011;42:174-8. 